\title{
Concordance, compliance, preference or adherence
}

\author{
This article was published in the following Dove Press journal: \\ Patient Preference and Adherence \\ 23 December 2010 \\ Number of times this article has been viewed
}

\author{
Scott Fraser \\ Sunderland Eye Infirmary, \\ Sunderland, UK
}

Correspondence: Scott Fraser

Sunderland Eye Infirmary, Queen

Alexandra Road, Sunderland,

SR2 9HP, UK

Tel +44 0I9I5699853

Email sfraser100@gmail.com
The realization that patients do not always do what their doctor recommends has led to a whole area of research looking into why this is so and how to counteract it. If we assume that the practitioner is right (an area of research in itself, of course!), then how do we get the patient to follow that advice? If you have high blood pressure, but don't take the tablets is this remiss or empowering? Are you ignoring your health needs or taking control of them?

As always, definitions are necessary so that everyone knows they are talking about the same thing. Medication-taking behavior has now spawned a lexicon of terms that are useful in the research setting, but lead to confusion outside of it. What is the difference between concordance and compliance, or between adherence and persistence?

A physician-led approach to prescribing treatment came to be described as "compliance" in the medical literature of the 1950s. This word quickly became unpopular for its judgmental overtones and alternatives were sought. "Adherence" was then introduced and was used interchangeably with compliance. Amongst a number of problems, the terms "nonadherence" and "noncompliance" make no distinction between someone who takes some or none of their prescribed treatment. Additionally, these terms shed no light on the reasons or motivations for a patient's medication-taking behavior.

Rates of refilling for prescriptions have been used as a method of measuring adherence and is also another means of testing "persistence". This term is relatively recent, and describes the duration of continuous medication use. In clinical practice, the term is probably of limited value to physicians when describing patient behavior and may serve a more useful purpose in the pharmaceutical industry, as it commonly refers to how frequently a patient will collect a prescription for a certain treatment with little regard to its effectiveness or whether it is actually taken or not.

It is increasingly understood that clinicians require a far greater appreciation of the patient's perspective of their condition and the need to foster a working partnership to achieve this appreciation. The creation of an agreement between parties as to how to move forward, instead of a mere giving and receiving of instructions, is perhaps the most positive approach. Termed "concordance", this concept has seen an increased usage in the past decade or so to describe a more equal relationship between physician and patient. It describes a change in culture and builds on the idea of a shared responsibility. The emphasis is more on setting out the goals of therapy and not arbitrarily enforcing a treatment regime. 
Of course, the bottom line is that it doesn't matter what you call it as long as the patient takes the correct medication at the correct time and at the correct dose. Cognitive and social problems have an impact upon this as do the frequency and total number of medications the individual takes. All these need to be taken into consideration when prescribing and reviewing medications, but intuitively it seems much more likely that the patient who understands why they are taking a treatment is much more like to take it. This is why I think that the term we should all use is in fact the one we are actually aiming for anyway - concordance.

\section{Publish your work in this journal}

Patient Preference and Adherence is an international, peer-reviewed, open access journal focusing on the growing importance of patient preference and adherence throughout the therapeutic continuum. Patient satisfaction, acceptability, quality of life, compliance, persistence and their role in developing new therapeutic modalities and compounds to optimize clinical outcomes for existing disease states are major areas of interest. This journal has been accepted for indexing on PubMed Central. The manuscript management system is completely online and includes a very quick and fair peer-review system. Visit http://www.dovepress.com/ testimonials.php to read real quotes from published authors. 